\title{
Preliminary results of the summer and winter companies 2019-2020 on Lake Baikal in the framework of the RFBR project for the study of eddies that form ice rings
}

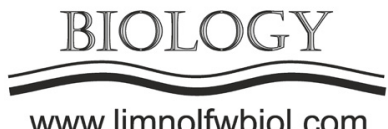

\section{Zyryanov V.N. ${ }^{1}$, Granin N.G. ${ }^{2}$, Zyryanov D.V. ${ }^{1 *}$, Chebanova M.K. ${ }^{1}$, Aslamov I.A. ${ }^{2}$, Gnatovsky R.Yu. ${ }^{2}$, Blinov V.V. ${ }^{2}$}

${ }^{1}$ Water Problems Institute, Russian Academy of Sciences, Gubkina Str., 3, Moscow, 119333, Russia

${ }^{2}$ Limnological Institute, Siberian Branch of the Russian Academy of Sciences, Ulan-Batorskaya Str., 3, Irkutsk, 664033, Russia

\begin{abstract}
Preliminary results of joint expeditions with the Laboratory of Hydrophysics of the Limnological Institute of the Siberian branch of RAS to study eddies, responsible for the appearance of rings on ice of Lake Baikal are presented. We conducted summer and winter campaigns in two areas of the Lake: near the Cape 'Nizhnee Izgolovye', and in the southern part of Baikal near Kultuk settlement.
\end{abstract}

Keywords: Ice thickness, ground-penetrating georadar, ice rings, CTD, under-ice hydrodynamics

In 2019, work was carried out in the summer from the R/V G.Yu. Vereshchagin with the launch of two buoys of the French satellite network Argos (CNES, France) with RBR temperature recorders (Canada) placed at several depths down to $200 \mathrm{~m}$. We also measure conductivity-temperature-depth (CTD) profiles to the very bottom of Lake Baikal using SBE25 probe (Sea Bird Electronics, USA). We launched the buoys between 07.26.2019 and 08.08.2019 in area of Cape 'Nizhnee Izgolovye', where an ice ring is often observed in winters.

Winter works in 2020 were fulfilled in the area of South Baikal. For the first time, we made the studies using ground-penetrating radar (GPR) «PikorLed» (Russia), which makes it possible to measure the thickness from moving vehicle with $1 \mathrm{~cm}$ accuracy.

Until mid-March, the LIN SB RAS all-terrain tracked vehicle was used and then survey continued from the Khivus hovercraft (Aerohod company, Russia).

Particular attention was paid to the development of the method of working with the GPR in the field, revealing with its help, large-scale spatial irregularities in the ice thickness in South Baikal (Granin, 2015; Kouraev et al., 2019). The hydrophysical characteristics were measured using a CTD water quality probe RINKO AAQ177 (JFE instruments, Japan), the velocities and directions of the currents were measured with an Infinity-EM electromagnetic current meter (JFE instruments, Japan), the immersion depth of the current meter was recorded using a pressure sensor from an RBRduet logger (RBR, Canada). The distribution of ice thicknesses and under-ice hydrodynamics were obtained in the southern part of Lake Baikal near Kultuk settlement.

Obtained distribution of ice thickness in the southern tip of Lake Baikal indicates the existence of an annular area of thinner ice (Fig. 1A), although it was still not traced on satellite images. Measurements of temperature and currents were fulfilled by Aslamov I.A., Gnatovsky R.Yu. and Blinov V.V. (LIN SB RAS) in this area in April 2020 (Fig. 1B), showed the presence of an anticyclonic eddy, which is the reason for the subsequent appearance of the ring on MODIS satellite images (Granin et al., 2015; Zyryanov, 1985).

The reported study was supported by RFBR research project 19-05-00522.

\section{References}

Granin N.G., Kozlov V.V., Tsvetova E.A. et al. 2015. Field studies and some results of numerical modeling of ring structures on the ice of Lake Baikal. Doklady Earth Sciences 461(3): 316-320. DOI: 10.1134/S1028334X15030204

Kouraev A.V., Zakharova E.A., Rémy F. et al. 2019. Giant ice rings on lakes and field observations of lens-like eddies in the Middle Baikal (2016-2017). Limnology and Oceanography 64(6): 2738-2754. DOI: 10.1002/lno.11338

Zyryanov V.N. 1985. Teoriya ustanovivshikhsya okeanicheskikh techeniy [The steady ocean current theory]. St-Petersburg: Gidrometeoizdat. (in Russian) 

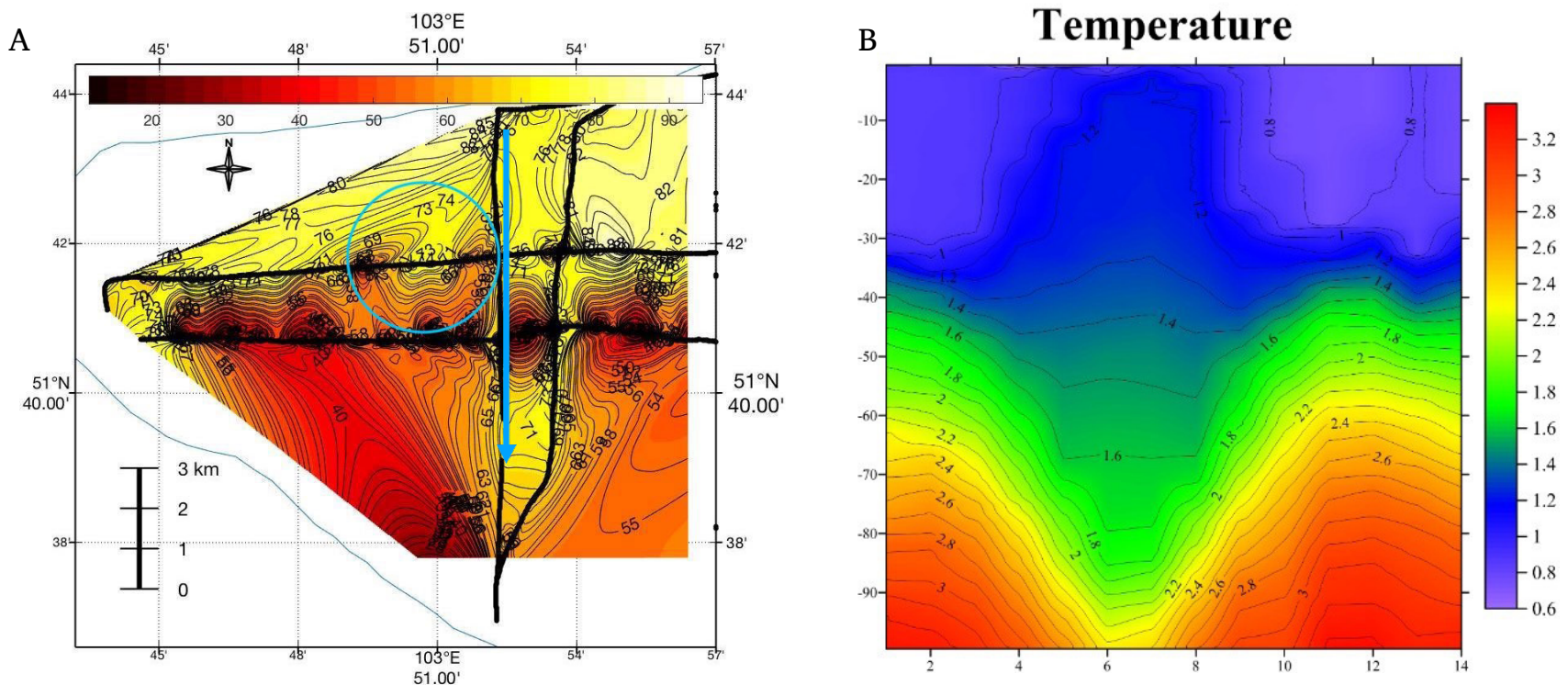

Fig.1. A: GPR «Picor-Led» scan of the ice thickness in South Baikal made in 03-04.04.2020. The circle denotes the ice ring location and size. B: The temperature profile along the blue arrow in 1A. 